\title{
THE ROLE OF SCHWANN CELLS AND MACROPHAGES IN THE REMOVAL OF MYELIN DURING WALLERIAN DEGENERATION
}

\author{
Ming Hu Han, Ying Jie PIAO*, De Wan GUO and Kazuo OGaWA** \\ Department of Computer Science and Department of Central Laboratory*, \\ the First Medical College of PLA, Guangzhou, P.R. China and \\ Department of Anatomy**, Kyoto University \\ Faculty of Medicine, Kyoto 606
}

Received for publication March 15, 1989

\begin{abstract}
Axonal changes, in particular the breakdown and removal of the myelin sheath, were studied using morphological method and cytochemical technique in the sciatic nerves of rats following transection. The details of axonal loss were examined during the first few days after transection. Axonal degradation was immediately accompanied by the fragmentation of the myelin sheath. It was found that: (a) a part of the myelin sheath separated from Schwann cells and smashed into debris, then the myelin debris was phagocytosed and digested by macrophages at endoneurial space; the others, most of the myelin sheath, remained within Schwann cells until being digested; (b) both small debris of myelin sheath (SDMS) and large membrane-bound myelin debris (LMBMD) were found in Schwann cells; acid phosphatase (AcPase) activity was detected in SDMS earlier than in LMBMD; (c) macrophages were found in myelin sheath tubes; they participated in removing a part of degenerating axons. Observation confirmed that Schwann cells had no ability to actively phagocytose myelin, that the majority of myelin debris were removed by Schwann cells, and that the minority of them were dealt with by macrophages. The ability of Schwann cells to digest myelin debris suggested that Schwann cells play a crucial role in vivo in removing myelin debris and that the process of myelin debris in Schwann cells might be significant for their mitotic activity.
\end{abstract}

Much evidence has shown that the digestive process of myelin is intimately related to Schwann cell proliferation $(1,2,5,8,11,20,21)$. The removal of the myelin sheath elicited proliferative response of Schwann cells $(5,12,16)$. However, the removal process of the myelin sheath during Wallerian degeration is not completely clear and there is still considerable controversy as to the type of cells involved in the removal. Many investigators have suggested that only Schwann cells $(9,12)$, or macrophages $(4,6,17)$ or both cell types $(5,13,15)$ participate in the removal of the myelin sheath during nerve degeneration. Some investigators $(5,12,13,19)$ found that Schwann cells and macrophages contained myelin fragments, but the source of the myelin fragments within the Schwann cells is still uncertain. Holtzman and Novikoff (9) suggested that the myelin sheath was degraded during Wallerian degeneration within digestive vacuoles of Schwann cells, but not within invading histiocytes, and that the digestive vacuoles might be autophagic vacuoles. Beuche 
and Friede (4) observed that nerve degeneration proceeding without non-resident cells showed no Schwann cell proliferation and no active removal or digestion of myelin. They believed that Schwann cells did not phagocytose myelin debris to any extent. Crang and Blakemore (6) supported this view, but they reported that in explant cultures without macrophages Schwann cell proliferation occurred, and they considered that myelin sheath breakdown and Schwann cell division in Wallerian degeneration were two separate processes. In contrast, on the basis of the ability of cultured Schwann cells to phagocytose myelin rapidly, Bigbee (5) advanced that in vivo Schwann cells might contribute to the fragmentation and removal of myelin. Recently, Baichwal (2) confirmed that supernatants derived from peritoneal macrophages incubated with myelin membrane fraction were mitogenic for cultured Schwann cells. The series of results appear to be contradictory. One can imagine that the mitogenic factor for Schwann cell multiplication may be concerned with the process of myelin by Schwann cells, or macrophages, or both cells. It seems necessary to further investigate the removal events of the myelin sheath in vivo during Wallerian degeneratipn.

In order to elucidate the role of Schwann cells and macrophages in the removal of the myelin sheath, the process of myelin debris (the first week post-transection) and the lysosomal activity (for two weeks post-transection) were studied using the morphological method and cytochemical technique.

\section{MATERIALS AND METHODS}

Experiments were performed on adult Wistar rats of either sex, weighing 180$250 \mathrm{~g}$, anaesthetized by intraperitoneal injection of sodium pentobarbital. Sciatic nerves were exposed from the sciatic notch to the tibial-peroneal bifurcation and transected at sites near the sciatic notch, and then a $5 \mathrm{~mm}$ segment of nerve was removed to prevent proximal stumps from linking with distal stumps. The sciatic nerves were re-exposed to derive nerve tissues from distal stumps for pure morphological study at $0,0.5,1,1.5,2,3,4,5,6$ and 7 days (12) and for cytochemical study at 5, 10 and 15 days post-transection (10). The tissues were cut into approximately $1 \times 2 \mathrm{cu} \mathrm{mm}$.

For the pure morphological study, tissue blocks were immersed for $60 \mathrm{~min}$ in the fixative containing $3 \%$ glutaraldehyde in $0.1 \mathrm{M}$ phosphate buffer at $\mathrm{pH} 7.4$, with $10 \%$ sucrose. This was followed by postfixation in cold $1 \%$ osmium tetroxide and dehydration through graded acetones and then embedding in Spurr's resin. All processes were carried out at room temperature.

For the cytochemical study, tissue blocks were fixed for $60 \mathrm{~min}$ using $3 \%$ glutaraldehyde in $0.1 \mathrm{M}$ sodium cacodylate buffer at $\mathrm{pH} 7.4$ with $10 \%$ sucrose. Then blocks were cut at $40 \mu \mathrm{m}$ thickness with a Microslicer (Dosaka EM Co., Ltd., Japan) and washed with the same buffer. The above operation was completed at $0^{\circ} \mathrm{C}$, and the following processes, at room temperature. Acid phosphatase (AcPase) activity was detected after Gomori. After the reaction, the sections were postfixed by $1 \%$ osmium tetroxide for $\mathbf{4 0} \mathrm{min}$ and dehydrated in graded acetone series and embedded in Spurr's resin.

Transverse and longitudinal sections were cut with an Ultrotome (LKB Co., Ltd., Sweden). Pure morphological sections were stained with uranyl acetate and 
lead citrate. Cytochemical sections were directly observed without staining. All sections were examined with a JEM $1200 \mathrm{EX}$ electron microscope operated at $80 \mathrm{KV}$.

\section{RESULTS}

\section{Axonal changes of myelinated fibres}

During Wallerian degeneration, axons underwent the following changes. At day 0.5 post-transection, the first response of axons to nerve transection was separation from their myelin sheath. Then the separated sites became small vacuoles which could get into axoplasm (Figs. 1, 2). From 0.5 to 1.5 days vacuoles rapidly increased in axoplasm. With vacuole formation, myelin debris occasionally got into vacuoles, and vacuoles carried the myelin debris into axoplasm (Fig. 1). From day 2 onwards, the increase of axoplasmic vacuoles was immediately accompanied by a series of events in axoplasm: accumulation of mitochondria, loss of mitochondrial cristae, swelling of mitochondria and axoplasmic condensation. In longitudinal sections, it was observed that a degenerating axon was not a continuous entirety in internode. In addition to loss of contact with the myelin sheath, a degenerating axon was divided into many segments within a myelin sheath tube. Following concentration of degenerating axons, the myelin sheath began to crease. Therefore, there were no axons in some transverse sections. At day 4 post-transection, almost all of axons were digested. Infrequently, one or two macrophages were found within the myelin sheath tubes (Fig. 3). With the loss of degenerating axons macrophages were not found again within the myelin sheath tubes. These observations suggested that macrophages participated in clearance of a part of degenerating axons.

\section{Removal of myelin sheath}

In the course of nerve degeneration, myelin sheath had experienced tremendous changes of conformation. Accompaning disorganization of axons, the myelin sheath began to fold at day 2 post-transection. While the structure of the myelin sheath started to change, Schmidt-Lantermann clefts easily separated. The two parts of separated myelin lamellae sometimes formed two concentric circles. At day 3, most of the myelin sheath further folded within Schwann cells. From day 3 onwards, the myelin sheath commenced to fragmentate. But in transverse sections it was found that the outer-most myelin sheath membranes in the internode were not easy broken (Fig. 4). The membranes formed a boundary between the inner myelin debris and the Schwann cell's cytoplasm. Actually, the large membrane-bound myelin debris (LMBMD) within the Schwann cells was a digestive vacuole. Acid phosphatase (AcPase) activity detection showed that AcPase reactive products were distributed along

Frg. 1. Showing small vacuoles (arrows) within an axon. Myelin debris (arrowhead) is in a vacuole. At day $1 . \times 22,000$

FIG. 2. A small vacuole (arrow) is getting into axoplasm. A small round myelin debris (arrowhead) is seen in the axon. At day $1 . \times 11,800$

Fig. 3. A macrophage is in a myelin sheath tube. Myelin lamellae is a continuous entirety. A heterophage (arrow) is seen in macrophage's cytoplasm. At day $6 . \quad \times 3,400$

Fig. 4. Many small debris of myelin sheath (SDMS) (arrows) are at the periphery of a large membrane-bound myelin debris (LMBMD). Outer boundary (arrowhead) of LMBMD is distinct. At day $5 . \times 5,200$ 


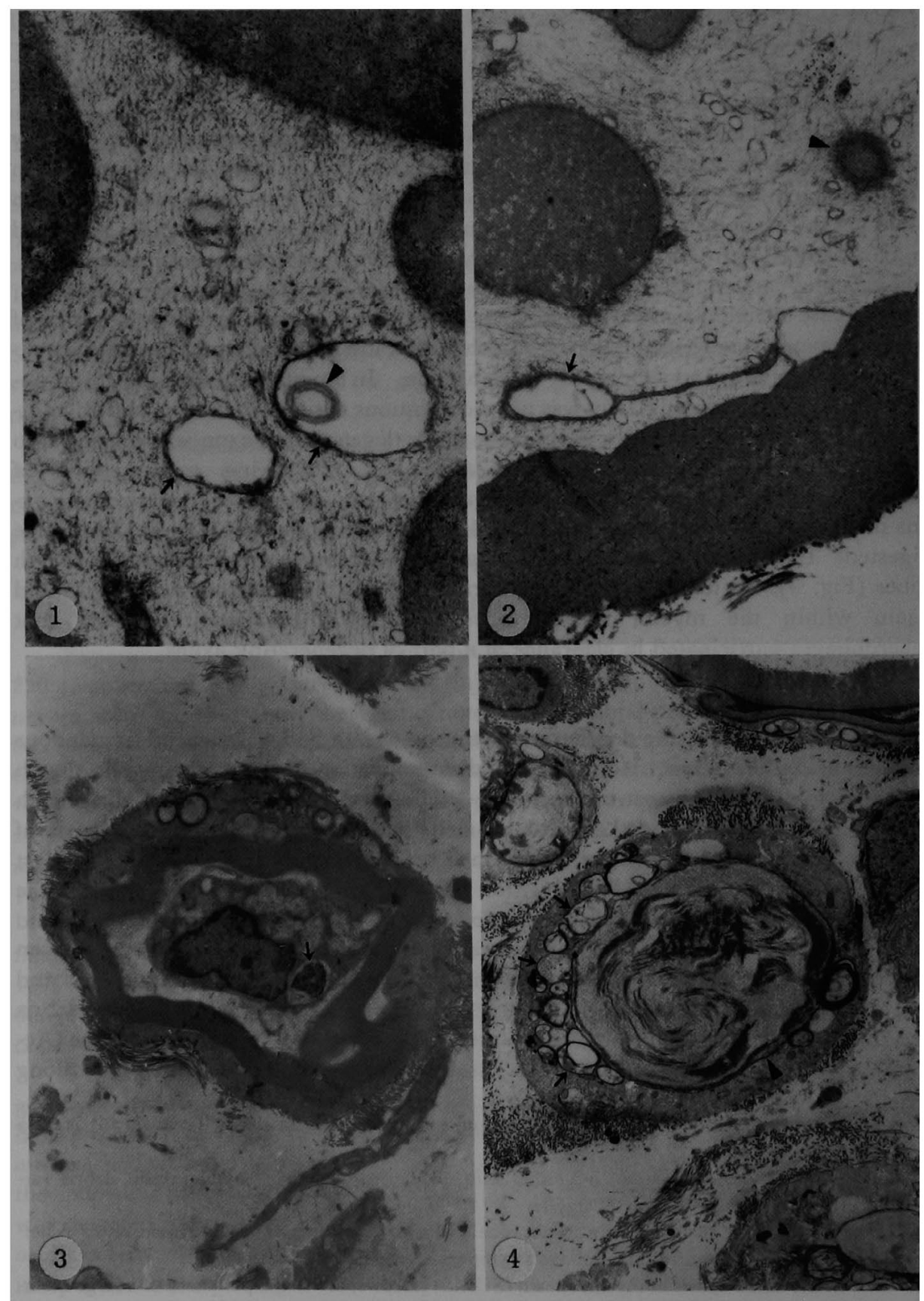




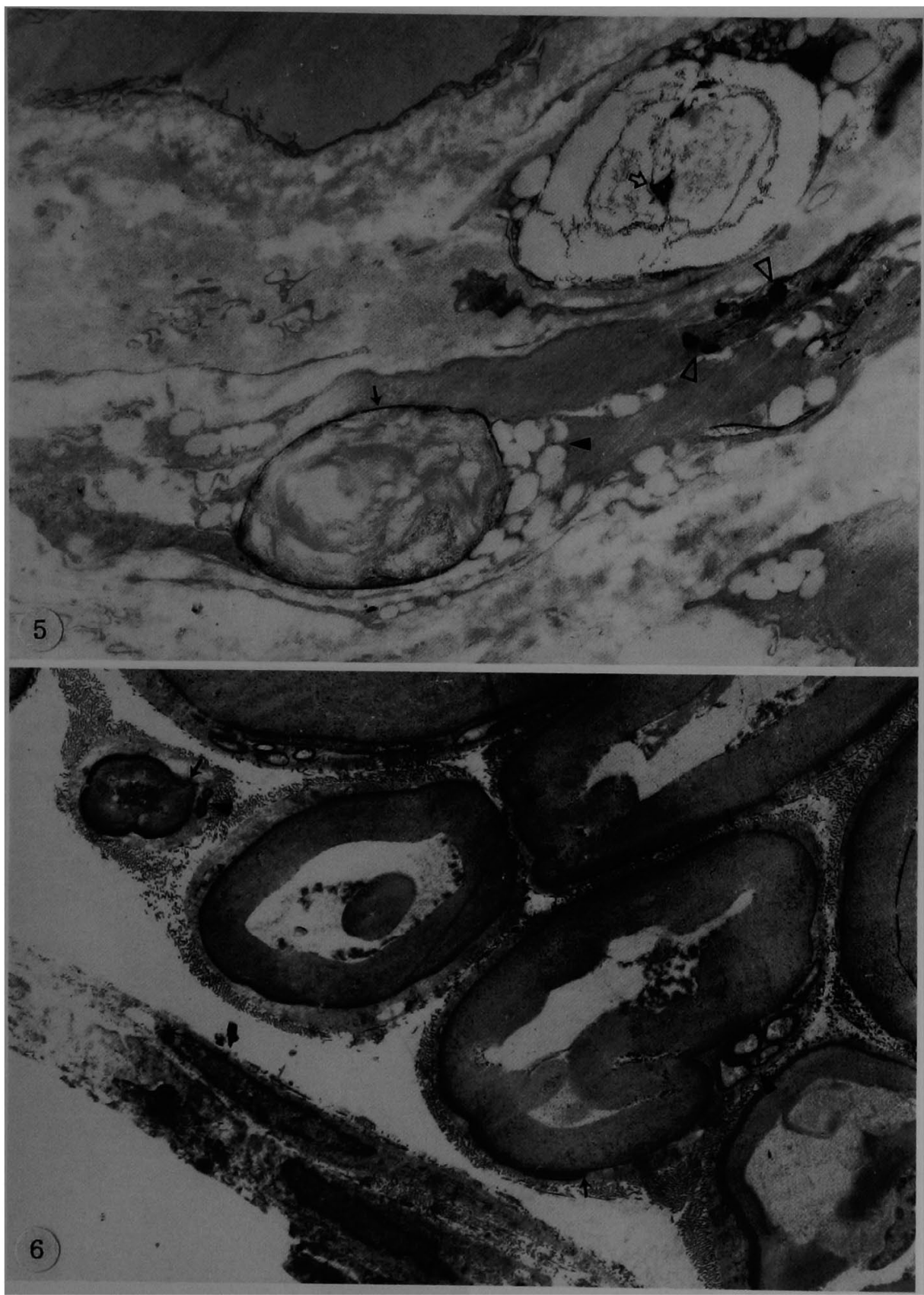

Fic. 5. AcPase reactive products are distributed along the boundary of LMBMD (arrow). Some reactive products are deposited within LMBMD (white arrow). Many low electron-dense vacuoles (arrowhead) and lysosomes (white arrowhead) are also seen. At day $15 . \quad \times 6,000$

Fig. 6. Showing formation of SDMS. Outer membranes of myelin lamellae are broken (arrows). The broken myelin lamellae wind and then form many SDMS (arrowheads). At day $4 . \quad \times 6,600$ 


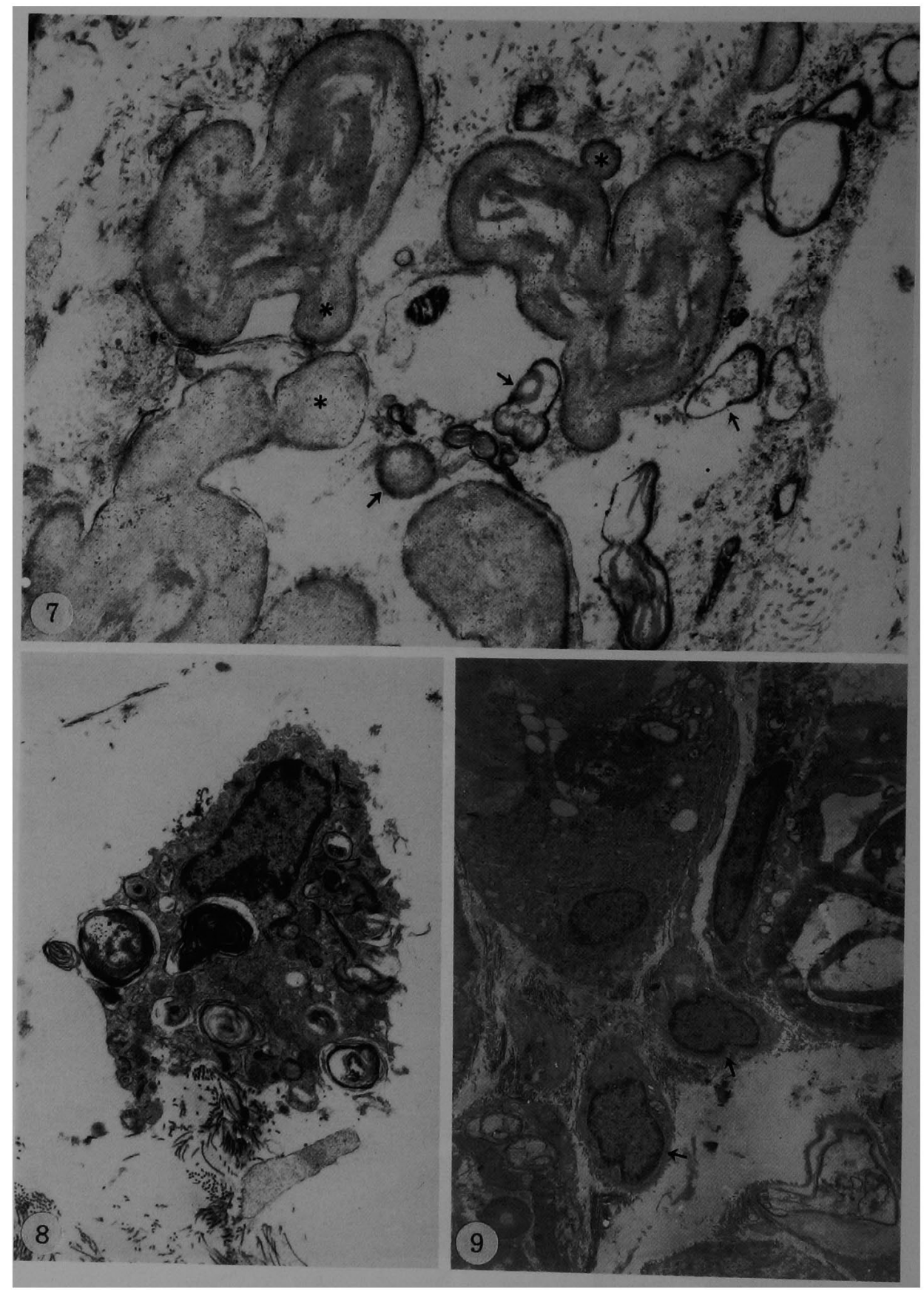

Fic. 7. Showing separated myelin sheath. There are many myelin ovoids (arrows) at endoneurial space. Asterisks show that myelin sheath is budding and becoming myelin ovoid. At day 4 .
$\times 24,500$ $\times 24,500$

Fic. 8. A macrophage is phagocytosing myelin debris (myelin ovoids). At day $7 . \quad \times 8,800$

FIG. 9. Showing young cells (arrows). At day $6 . \times 3,200$ 


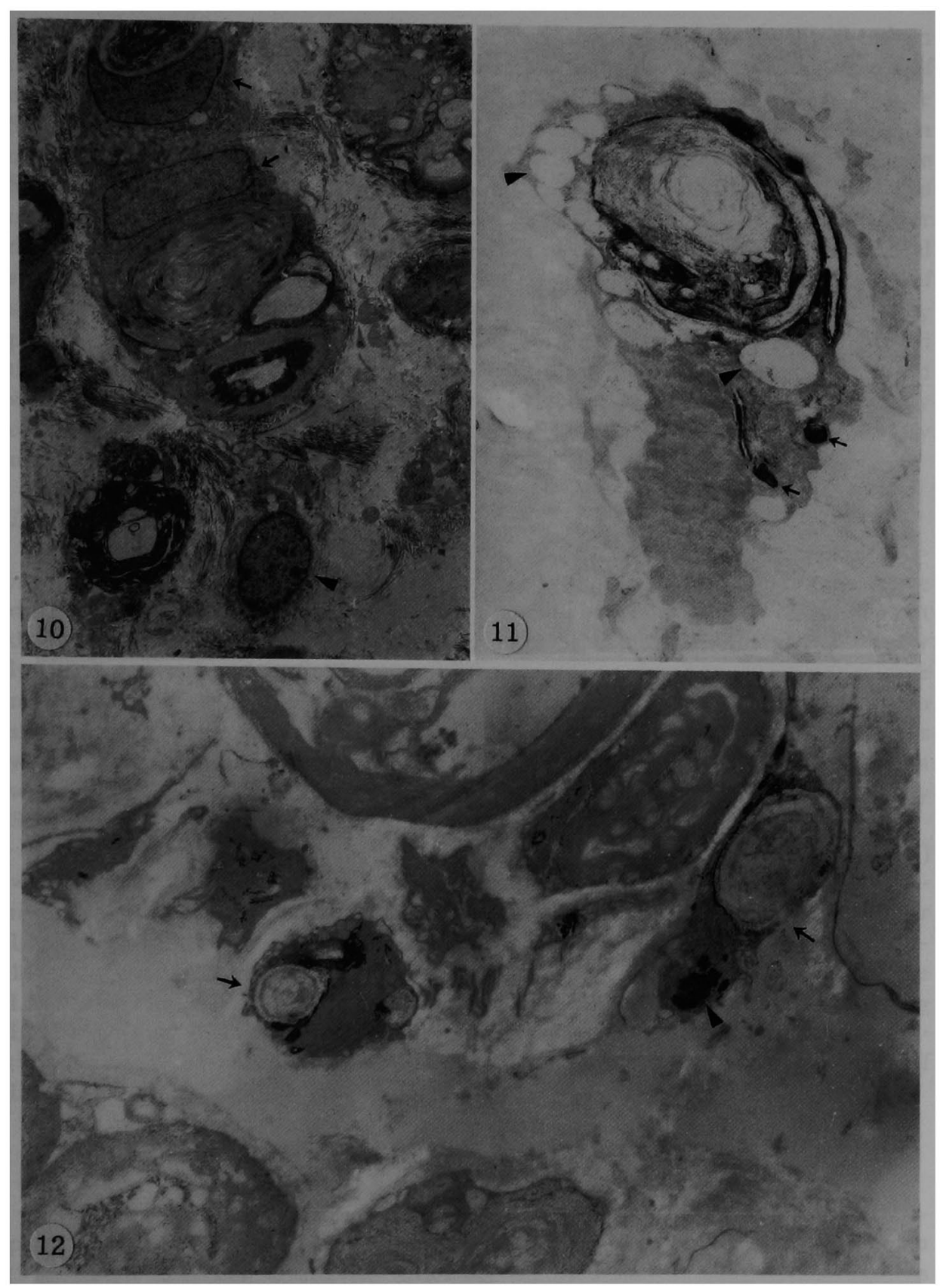

Fic. 10. Schwann cells with nuclei (arrows) bound myelin sheath. A young cell (arrowhead) is also seen. At day $6 . \times 2,500$

Fig. 11. A LMBMD is being digested. Lysosomes are clear (arrows). Many low electron-dense vacuoles (arrowheads) appear at periphery of LMBMD. At day $15 . \times 9,000$

Fig. 12. Two macrophages (arrows) are phagocytosing myelin debris. Lysosomes are seen (arrowhead). At day 5. $\times 5,000$ 


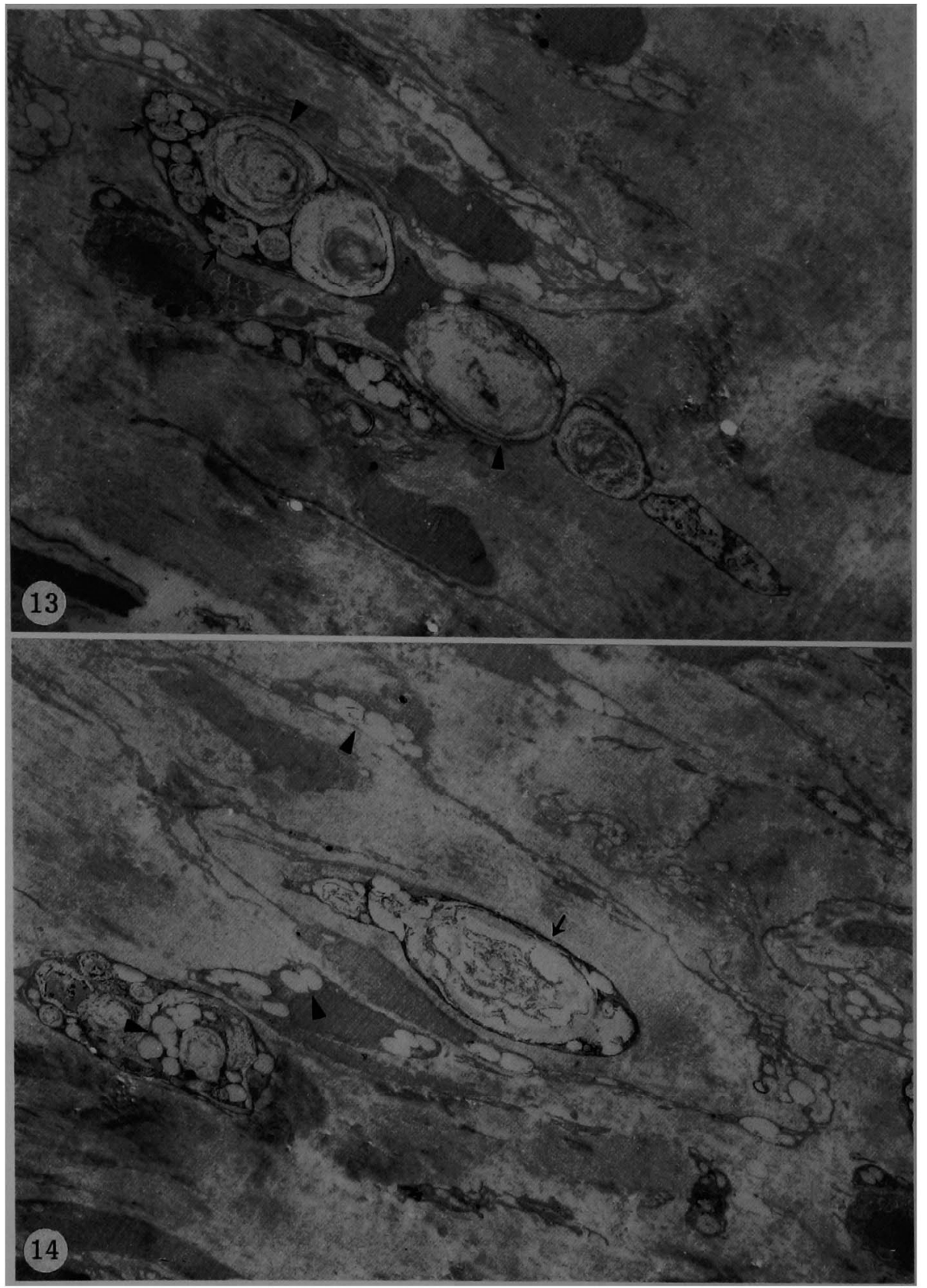

FIG. 13. SDMS (arrows) are being digested within Schwann cells. Some LMBMD (arrowheads) have no obvious AcPase reactive products on them. At day 10 . $\times 3,300$

FIG. 14. A boundary of LMBMD (arrow) shows AcPase reaction positive. Many low electrondense vacuoles (arrowheads) are seen. At day $10 . \times 3,300$ 
the boundaries (Fig. 5). Our observation showed that most of the myelin sheath in the internode had such boundaries. It was also found that many small debris of myelin sheath (SDMS) appeared at the periphery of the LMBMD (Fig. 4). The SDMS were formed by fragments of outer myelin lamellae (Fig. 6), and the formation of SDMS was prior to that of LMBMD. No wrapping membranes bound the SDMS. On the other hand, in addition to myelin sheath remaining within Schwann cells, others were separated from Schwann cells after disorganization of axons. After that, they escaped from basement membrane tubes and got into the endoneurial space. These free myelin sheaths folded repeatedly, and then made a great number of small round bodies (myelin debris) (Fig. 7). These round debris were finally phagocytosed and digested by macrophages (Fig. 8). These observations indicated that during Wallerian degeneration most of myelin sheath in the internode remained within Schwann cells and was finally digested by Schwann cells and that the minority of myelin debris (myelin sheath separated from Schwann cells) removed by macrophages.

\section{Lysosomal activity of Schwann cells}

The first impression of Schwann cells was that their cytoplasm acquired increasing ribosomes and rough endoplasmic reticulum, and basement membranes were distinct. At day 1.5 post-transection, the number of lysosomes slightly increased. At day 2, the cisternae of endoplasmic reticulum of Schwann cells enlarged and many lysosomes were found in Schwann cell cytoplasm. At day 3 post-transection, the myelin sheath bound by Schwann cells with nuclei were rare, and most of myelin sheaths were surrounded only by intact cytoplasm of Schwann cells. Young cells were seen by chance at endoneural space at day 4 post-transection. At the end of a week post-transection, many young cells (Fig. 9) and many myelin sheaths bound by Schwann cells with nuclei appeared (Fig. 10).

At day 5 post-transection, many lysosomes (AcPase reaction-positive bodies) were presented within Schwann cells and macrophages (Figs. 5, 11, 12). AcPase activity reaction-positive products often appeared at the periphery of SDMS or LMBMD within Schwann cells and in heterophagosomes of macrophages (Figs. 1214). At day 15 post-transection, some reactive products were found within the LMBMD (Fig. 5). Many low electron-dense vacuoles were found around digesting LMBMD (Figs. 5, 11). On the basis of analysis of AcPase reaction product distribution, it might be concluded that SDMS were digested prior to the digestion of LMBMD within Schwann cells.

\section{DISCUSSION}

Among all events in vivo following nerve transection, axonal response first appeared. The changes of mitochondria were observed by Nathaniel (12), Holtzman (9), O'Daly (13) and Grang (6). O'Daly reported that Wallerian degeneration started with axoplasmic condensation and accumulation of mitochondria. However, in our observation, the first response of axons to nerve transection was that many small vacuoles were produced in the axoplasm. We believe that this response showed atrophy of axons and loss of axoplasm. In addition, the appearance of macrophages within myelin sheath tubes indicated that macrophages participated in the process of 
disorganized axons. Macrophages might infiltrate the myelin sheath tubes from the broken nodes of Ranvier.

In order to interpret the cause of Schwann cell division, many investigators engaged in study on process of myelin debris because they believed that Schwann cell proliferation was intimately related to the process of myelin debris. Thus further study on the process of myelin debris seems to be more important. De Duve and Wattiaux (7) described that lysosomes played a central role in intracellular digestive processes. On the basis of this view and the fact that among the more than 60 lysosomal acid hydrolases, acid phosphatase (AcPase) is most commonly used as a lysosomal marker (3), we examined lysosomal activity of Schwann cells and confirmed that the digestive process of myelin debris was completed within Schwann cells. According to analysis of AcPase reactive product distribution, the small debris of myelin sheath (SDMS) and the large membrane-bound myelin debris (LMBMD) (Figs. 4, 5) were digestive vacuoles. Moreover, it should be noted that the boundary membranes of LMBMD were derived from myelin lamellae but not from others. The evidence that AcPase reactive products were found within LMBMD (Fig. 5) showed that the boundary of LMBMD was sometimes broken. Fragments of myelin sheath within digestive vacuoles (LMBMD) were Schwann cell's own myelin sheath. The fragments were not derived by Schwann cell active phagocytosis. Although real wrapping membrane of autophagic vacuoles (autophagosomes) is derived from intracellular membrane structures or cell membrane, here we yet consider these vacuoles surrounded by outer myelin lamellae as autophagosomes. Furthermore, we also consider the SDMS as autophagosomes. Actually, we observed that most of myelin sheaths were digested within Schwann cells by autophagy. It also should be noticed that the formation and digestion of SDMS were prior to that of LMBMD. Holtzman and Novikoff (9) first described the digestive process of myelin sheath within Schwann cells in 1965. They stated that myelin was not phagocytosed in the usual manner by Schwann cells, and the fragmentation of myelin sheath was carried out within Schwann cells. Our results support these views. However, their view that rejection of myelin fragments and final phagocytosis by Schwann cells were not major phenomena is different from ours. Our observation indicated that a part of myelin sheath, in particular myelin sheath near the nodes of Ranvier, was usually separated from Schwann cells. These free myelin sheaths made a great number of small round myelin debris (myelin ovoids or globules). These myelin ovoids were subsequently phagocytosed by macrophages at endoneurial space. Ohmi (14) observed the same process in 1961. Bigbee (5) reported that in cultured condition Schwann cells phagocytosed myelin slower than macrophages. In in vivo experimental condition, our results indicated that most of myelin fragments remained within Schwann cells and were digested by them, and that the others were separated from Schwann cells and phagocytosed by macrophages.

A few young cells were found at day 4 post-transection. It was reasonable to suppose that these young cells were Schwann cells. At the end of a week post-transection, the young cells were often found at the endoneurial space. Moreover, the LMBMD surrounded by Schwann cells with nuclei were also often seen. These results suggested that Schwann cells had proliferated. In our opinion, the following events occurred. First, Schwann cells received some stimuli (mitogenic factor), then separated from their myelin sheath by way of denucleation (18). On one hand, the majority of Schwann cells' cytoplasm surrounded and digested their myelin debris. On the other 
hand, Schwann cells proliferated within basement membrane tubes. Secondly, a part of young Schwann cells escaped from basement membrane tubes and got into endoneurial space, and others remained within basement membrane tubes (6). However, it is not clear whether the mitogenic factor is from macrophages or from Schwann cells. Baichwal (2) found myelin-enriched fraction stimulated macrophages to produce mitogenic supernatants for Schwann cells. This result showed that lysosomal processing of myelin membrane within macrophages was necessary for the production of mitogen for Schwann cells. In contrast, Bigbee (5) confirmed that lysosomal processing of myelin membrane within Schwann cells was necessary for the production of mitogen for Schwann cells. Our evidence confirmed that most of the myelin debris was removed by Schwann cells. Therefore, in vivo digestive processing or lysosomal processing of myelin debris within Schwann cells might be significant for their mitotic activity.

\section{ACKNOWLEDGMENTS}

We are very thankful to Mr. Lian Pu LIU, Mr. Lian Bing AN and Mr. Huan Cai XIAO for their technical assistance and to Mrs. Wen HU for her valuable discussions. Thanks are also due to Miss Chao Ling XU for her secretarial work.

\section{REFERENCES}

1. Baichwal, R. R., Bigbee, J. W. and DeVries, G. H.: Schwann cell proliferation in response to a soluble mitogenic factor from myelin stimulated macrophages. Soci. for Neurosci. Abstracts 16; 394, 1986.

2. Baichwal, R. R., Bigbee, J. W. and Devries, G. H.: Macrophage-mediated myelin-related mitogenic factor for cultured Schwann cells. Proc. Natl. Acad. Sci. USA 85; 1701-1705, 1988. Neurobiology.

3. Bainton, D. F.: The discovery of lysosomes. J. Cell Biol. 91; 66-76, 1981.

4. Beuche, W. and Friede, R. L.: The role of non-resident cells in Wallerian degeneration. $J$. Neurocytol. 13; 767-796, 1984.

5. Bigbee, J. W., Yoshino, J. E. and DeVries, G. H.: Morphological and proliferative responses of cultured Schwann cells following rapid phagocytosis of a myelin-enriched fraction. $J$. Neurocytol. 16; 487-496, 1987.

6. Crang, A. J. and Blakemore, W.F.: Observations on Wallerian degeneration in explant cultures of cat sciatic nerve. J. Neurocytol. 15; 471-482, 1986.

7. De Duve, C. and Wattiaux, R.: Functions of lysosomes. Ann. Rev. Physiol. 28; 435-492, 1966.

8. Hall, S. M. and Gregson, N. A.: The effects of mitomycin $C$ on the process of regeneration in the mammalian peripheral nervous system. Neuropathol. Appl. Neurobiol. 3; 65-78, 1977.

9. Holtzman, E. and Novikoff, A. B.: Lysosomes in the rat sciatic nerve following crush. J. Cell Biol. 27; 651-669, 1965.

10. Krstic, R. V.: Illustrated Encyclopedia of Human Histology. Spring-Verlag, Berlin, Heidelberg Press, 1984, p. 285.

11. Meador-Woodruff, J. H., Yoshino, J. E., Bigbee, J. W., Lewis, B. L. and DeVries, G. H.: Differential proliferative responses of cultured Schwann cells to axolemma and myelin-enriched fractions. II. Morphological studies. J. Neurocytol. 14; 619-635, 1985.

12. Nathaniel, E. J. H. and Pease, D.C.: Degenerative changes in rat dorsal roots during Wallerian degeneration. J. Ultrast. Res. 9; 511-532, 1963. 
13. O'daly, J. A. and Imaeda, T.: Electron microscopic study of Wallerian degeneration in cutaneous nerves caused by mechanical injury. Lab. Invest. 17; 744-766, 1967.

14. Ohmi, S.: Electron microscopic study on Wallerian degeneration of the peripheral nerve. Zeit. für Zellforsch. 54; 39-67, 1961.

15. Pellogrino, R. F., Politis, M. J., Ritchie, J. M. and Spencer, P. S.: Events in degenerating cat peripheral nerve: induction of Schwann cell $S$ phase and its relation to nerve fiber degeneration. J. Neurocytol. 15; 17-28, 1986.

16. Romine, J. S., Bray, G. M. and Aguayo, A. J.: Schwann cell multiplication after crush injury of unmyelinated fibers. Arch. Neurol. 33; 49-54, 1976.

17. Schubert, T. and Friede, R. L.: The role of endoneurial fibroblasts in myelin degeneration. J. Neuropathol. Exp. Neurol. 40; 134-154, 1981.

18. Seki, M., Yoneyama, T. and Shirasawa, H.: Role of the reticular cells during maturation process of the erythroblast. Report II. Further observation on the denucleation process of erythroblast. Acta Path. Jap. 15(3); 303-316, 1965.

19. Williams, P. L. and Hall, S. M.: Chronic Wallerian degeneration-an in vivo and ultrastructural study. J. Anat. 109; 487-503, 1971.

20. Yoshino, J. E., Dinneen, M. P., Lewis, B. L., Meador-Woodruff, J. H. and DeVries, G. H.: Differential responses of cultured Schwann cells to axolemma and myelin enriched fraction. I. Biochemical studies. J. Cell Biol. 99; 2309-2313, 1984.

21. Yoshino, J. E., Mason, P. W. and DeVries, G. H.: Developmental changes in myelin-induced proliferation of cultured Schwann cells. J. Cell Biol. 104; 655-660, 1987. 